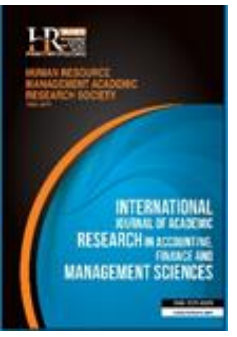

International Journal of Academic Research in Accounting, Finance and Management Sciences

Vol. 8, No. 4, October 2018, pp. 52-60

E-ISSN: 2225-8329, P-ISSN: 2308-0337

(C) 2018 HRMARS

www.hrmars.com

To cite this article: Sundari, S., Mediaty, Habbe, A.H., Harryanto (2018). Heuristic of Representativeness and Anchoring-Adjustment in Budgeting, International Journal of Academic Research in Accounting, Finance and Management Sciences 8(4): 52-60.

\title{
Heuristic of Representativeness and Anchoring-Adjustment in Budgeting
}

\author{
Sri Sundari ${ }^{1}$, Mediaty ${ }^{2}$, Abdul Hamid Habbe ${ }^{3}$, Harryanto ${ }^{4}$ \\ 12,3,4 Department of Accounting at the Faculty of Economics and Business at Hasanuddin University, Makassar, \\ Indonesia, ${ }^{1}$ E-mail: sriamir66@yahoo.com
}

\begin{abstract}
This study aims to examine and analyze the inaccuracy in determining the Local Revenue (PAD) budget estimation in the public sector for the upcoming period. When the budget compilers faced complex problems in arrangement the estimates of $P A D$, they will perform a decisions unit's budget estimates quickly and efficiently, just depend on the analyze information of PAD past and present. The method of analyzing this experimental research uses Two Way Analysis of Variance (ANOVA), one of the multivariate analysis techniques which serve to distinguish the average of the two groups of data by comparing the variance. The results of this study indicate that representativeness heuristic approach affects the bias that occurs or inaccuracy of PAD budget estimates, while anchoring-adjustment heuristic does not affect the bias or inaccuracy of the PAD budget estimates. Based on this, the budget compilers of PAD used a representativeness heuristic approach (existence of overreaction behavior) in predicting the amount of the PAD budget for the upcoming period. The heuristic approach is useful in determining the predictions of PAD budget in the public sector if the budget compilers have the knowledge competencies and adequate experiences in order to reduce the heuristic bias that occurs.
\end{abstract}

Key words Heuristic, representativeness, anchoring-adjustment, bias, budget estimation

\begin{tabular}{|c|c|c|}
\hline Received: & 15 Dec 2018 & (C) The Authors 2018 \\
\hline Revised: & 25 Dec 2018 & Published by Human Resource Management Academic Research Society (www.hrmars.com) \\
\hline $\begin{array}{l}\text { Accepted: } \\
\text { led Online: }\end{array}$ & $\begin{array}{l}30 \text { Dec } 2018 \\
9 \text { Jan } 2019\end{array}$ & $\begin{array}{l}\text { This article is published under the Creative Commons Attribution (CC BY 4.0) license. Anyone may } \\
\text { reproduce, distribute, translate and create derivative works of this article (for both commercial and non- } \\
\text { commercial purposes), subject to full attribution to the original publication and authors. The full terms of } \\
\text { this license may be seen at: http://creativecommons.org/licences/by/4.0/legalcode }\end{array}$ \\
\hline
\end{tabular}

\section{Introduction}

On arrangement budget process in the public sector, sometimes there is an inaccuracy in the amount of the budget or differences (bias) in predicting the budget (Halim, 2002; Kuncoro, 2008; Saputro et al., 2016 and Fadillah, 2017), so that a change in the budget has been set. This will disrupt the plans that have been prepared and accuse the performance appraisal. Many factors cause differences or biases in predicting the amount of the budget, including factors of individual behavior in the preparation of regional government budgets. The difference between budget realization with a predetermined fencing is a natural thing to happen. Nevertheless, the government still must analyze the cause of the difference of the budget so that more precise in projecting the budget on subsequent years.

Budget differences that occur due to, among others, the mis-estimation in determining the amount of the budget for the future. Budget mis-estimation can result from unreliable measurements or model use (McDermott, 1981). In addition, it can also occur due to a heuristic bias factor which is an inaccuracy in predicting future values (Habbe, 2017). This matter because decision makers do not use mathematical laws, ignore normative laws and tend to think pragmatically (Tversky and Kahneman, 1974).

Without ignoring the psychological factors of the individual, the causes of biased behavior are known as limitations in the ability to think (cognition) and emotionally which can lead to irrational behavior 
(Fagley, 1988). Cognition is usually defined simply as acquiring knowledge or information. In information processing there is an interaction between the internal and external conditions of the individual. Internal conditions are states in the individual that are needed to achieve the results of cognitive processes that occur in individuals. While external conditions are stimuli from the environment that affect individuals in the learning process. This information processing model is part of cognitive theory that studies the processing, storage and retrieval of information (Sweller and Sweller, 2006).

Inaccuracy in decision making or the bias in predicting the amount of budget realization, because the budgeting team uses shortcuts based on the amount of the budget last year. The reason for this limitation causes someone in financial decision making tends to use a heuristic approach, which is an approach or model in drawing conclusions quickly, but can lead to improper decisions or results that are not optimal due to cognitive limitations (Shefrin, 2007). In addition, heuristics can be interpreted as individual behavior in acting practically and simply in decision making in conditions of high uncertainty (Bloomfield et al., 2000, 2003).

Heuristik related to their representativeness bias that occurs or their inaccuracy to estimate the amount of the budget for future. Natural budget amounts set budget drafting team will depend on the amount of information on the budget realization in the previous years and years now. This phenomenon is a problem that requires proof empirically. Heuristic representativeness has been applied in decision making by investors in the capital market by previous researchers (Bloomfield et al., 2003 ; Kaestner, 2006; Boussaidi , 2013 and Habbe, 2017). The Results of research Habbe (2017) explained that with the use of heuristic representativeness and anchoring-adjustment can had an effect on behavior of investors in making decisions such as profit mis-estimation coming year and the company's stock price will come.

Kahneman and Riepe (1998) state that investors who experience bias representativeness tend to overreact when processing information to make transaction decisions. When the investor receives information, and the information is in accordance with his mental picture, the investor will behave abnormally and trigger the emergence of winner-looser anomalyphenomenon, namely the phenomenon of high stock price reversal becomes low, and the low becomes high.

The anchoring phenomenon has been used in various decision making (Presutti, 1995; Epley and Gilovich, 2006; Tamir and Mitchell, 2013; Strack et al., 2016 and Henrizi et al., 2017), such as predicting final assessment results using a different paradigm. The anchoring effect that occurs is one of the decisions that is influenced by the previous decision by adjusting it by comparing the target value produced by the standard which is set as an anchor and is expected and is believed to produce values that are close to the actual value (Mussweiler and Starck, 1999). If the adjustments made are insufficient, it will create a bias for the anchor value specified. Most of the results showed that a positive correlation between the use of the anchoring-adjustmentheuristicwith decisions on targeted assessment. The results of Henrizi et al.(2017) is the use of anchoring and adjustment heuristic approaches on the auditjudgment conducted by an external auditor. The results of this study are consistent with the results of research conducted by Joyce and Biddie (1981) and Asthon (1983) which states that the significance of the anchoring-adjustment heuristics approach used.

In public sector budgeting, the determination of the estimated amount of the Local Revenue (PAD) budget for the upcoming period influenced by many factors, including information on the realization of the amount of thePAD budget in the previous years (three consecutive years) and the realization of the amount of PAD budget in the current year that is not sufficient (there are external changes that are positive or negative). In addition, based on the Regulation of the Minister of Home Affairs of the Republic of Indonesia Number 33 of 2017 concerning guidelines for the preparation of APBD for Budget Year 2018, it is explained that the estimation of the Local Revenue (PAD) budget is influenced by the potential of regional taxes and levies and the growth of regional (macro) economy.

Based on the phenomenon there is always a difference between the Local Revenue (PAD) budgeted at the beginning of the period with the realization of Local Revenue (PAD) at the end of the period, then the purpose of this study is to analyze by testing experiments regarding the use of representativeness and anchoring-adjustment heuristics conducted by individuals in a team making up the public sector budget in determining the estimation of the public sector's Local Revenue (PAD) budget for the upcoming period. This motivates researchers to conduct research on the use of heuristics in budgeting, because in the previous research heuristic approach used in financial decision making (investors) and auditjudgment conducted by 
the auditor. The formulation of the problem in this study is whether the budget compiler in reducing the budgeting of Local Revenue(PAD)depends on the information on the realization of the PAD in the previous years and the realization of the current PAD. The results of this analysis are expected to provide useful contributions theoretically and practically. Heuristic representativenessand anchoring adjustment approaches are useful and have an important role in budget decision making such as determining the estimated Local Revenue (PAD) budget for the upcoming period. In addition, it adds insight to the budget compilers on public sector to increase their knowledge and experience in predicting the Local Revenue (PAD) to be more accurate and reduce the bias.

\section{Literature review}

\subsection{Cognitive Psychology Perspectives}

Cognitive psychology is very important in explaining human psychology, such as how to behave, how to obtain and process information (Rudolph and Popp, 2007), and how to formulate and solve problems faced (Martlin, 1998). In addition, cognitive psychology is a psychological approach to understanding human mental processes in influencing one's behavior (Kuhn and Siegler, 2006) or decision making (resolution of problems encountered) and explaining the symptoms experienced by individuals and being irrational in making decisions, but sometimes the decision results are biased (Nofsinger, 2005). By using the principles of cognition one can process information efficiently and well organized.

The cognitive approach is defined as the approach of human psychological phenomena by emphasizing the roles of perception, knowledge, memory and thought processes for human behavior, so cognitive psychology is often also called the psycho-information processing, which includes a series of information sequential and processing stages for the information. In information processing there is an interaction between internal and external conditions of the individual. This information processing model is part of cognitive theory which studies the processing, storage and retrieval of information (Rudolph and Popp, 2007). The information processing model explains how a person obtains a certain amount of information and can be remembered for a long time. In addition, information processing as a cognitive process consists of a series of processes, namely storage, retention, and information gathering (Galotti, 2004). In other words, cognitive psychology includes the decision of individual behavior in decision making based on a series of past information and this has an impact on the inaccuracy in decision making called heuristic bias .

\subsection{Representativeness Heuristic}

Representativenessheuristic according to Barberis et al. (1998) and Shefrin (2008) are the views of investors in making company business decisions based on stock's past performance as expectations that can represent the success of the company's performance for the future. However, investors will experience disappointment because they produce decisions that are not in accordance with the expected decision. This situation causes an underreaction (overreaction) selling price of shares in the capital market (Habbe, 2017).

Tversky and Kahneman (1974) state that there are impacts that occur when using bias representativeness in decision making, such as bias in predicting future decisions. Kannadhasan (2009) explains that representativeness describes a success of decisions made by managers that relate to the future and those decisions are made based on past experiences which are referred to as stereotypes. A person's tendency to make decisions is based on the amount of past information and additional new information. Strictly stated that this heuristic is used to assess a probability of conditions in real life (Nilsson et al., 2008), such as diagnoses performed by a doctor for patients who are estimated to have schizophrenia. These doctors tend to use representativeness heuristics, because these patients can be compared with other patients who have been diagnosed with schizophrenia or typical symptoms of schizophrenia (Garb, 1996). The use of heuristics is so entrenched in life, this is due to the existence of human thoughts or individuals who have a tendency to think practically, economically and quickly in their decision making (Kahneman and Tverski, 1973).

\subsection{Anchoring-AdjustmentHeuristic}


Anchoring-adjustment is the tendency of individuals to make estimates to depart at the initial value (anchor) which is then adjusted with new information (Tversky and Kahneman, 1972). In securities markets, investors tend to predict stock prices based on previous stock prices, predicting ROE with previous ROE. The tendency of investors to use the initial value (anchor) strengthens similarities stock prices from one day to the next. Shefrin (2007) explained that anchoring and adjustment heuristics occur when a person predicts that for the coming year will begin with a certain value as a reference and then make adjustments, but tend not to be able to make adequate adjustments. In other words, the implications for anchoring and adjustment heuristics are the presence of individuals in making decisions based on some information that has been used as a benchmark (initial information) in evaluating new information and making adjustments to the information, but because only based on information can reduce accuracy a decision taken (Hogarth and Einhorn, 1992).

Dependency (overreliance) on anchoring heuristics is not only done by laymen, but experienced individuals will unconsciously carry out an anchoring heuristic approach in their decision making, ie predicting the desired final assessment. This happens when the individual experiences conditions that do not allow to analyze data with a statistical approach with many calculations. The impact can certainly lead to misestimation. In other words, the use of anchoring heuristics cannot be avoided in various assessments or decision making, even though it can lead to errors or bias. This is due to the wrong anchor determination, so that the resulting decisions will be affected (Hardin, 1999). Heuristic anchoringadjustment is useful as a theoretical concept in explaining the effects of ambiguity on the assessment or probability can also influence individual behavior in taking a decision (Yadav, 1994).

\subsection{Approach in Budget Preparation}

Budgeting in public sector organizations is a fairly complicated stage and must be informed to the public for discussion, because the public sector budget is an instrument of accountability for the management of public funds and the implementation of programs financed with public funds. Therefore there is a need for supervision and control in its implementation. The process of public sector organization budgeting begins when the formulation and planning of strategies have been completed also includes aspects of public planning, control and accountability.

In line-item budgeting, the budget preparation process is only based on the magnitude of the previous year's budget realization, budget items according to their allocation are grouped in the items of the Activity Budget (MAK), consequently there are no fundamental changes to the new budget (Halim, 2002). This is often contrary to the real needs and interests of the community. In addition, the traditional budget preparation system only emphasizes the accountability of budget execution in accounting which includes the implementation of the budget, supervision of the budget and the preparation of the books. Budgeting in the previous traditional system has many shortcomings, especially the absence of an orientation towards results, the Indonesian government then recommends using a budgeting system with a performance approach. Performance-based budgeting system (performance-basedbudgeting) is a system that is currently growing rapidly and widely used by developed countries in the world as a replacement for the old budgeting system that is the system line-item budgeting. The process of drafting the public sector budget is determined based on budget policies and directives. All stages in the budget preparation process involve the political process and must seek agreement and approval of legislation to become a regulatory product (Government Regulation No.58, 2005). Budgeting is closely related to politics, because of the role of the legislature involved in the approval of the budget submitted by the executive (Chikeleze, 2002 and Amaechi et al., 2018). In addition, in the formulation of budgets there are several dimensions that influence it, namely the political, governance and public interest dimensions. Political dimension in the budget process includes the role of the regional parliament, the right prerogatif governments and intergovernmental transfer that is a region of the national government. The budget process includes the process of programming, formulation, debate and execution of approvals and monitoring (Del Valle et al., 2001).

\section{Hypothesis Development}

Based on the explanation above, the research hypothesis are: 
$H_{1}$ : The budgetcompilers in predicting the PAD budget estimation for the upcoming period uses the representativenessheuristic approach.

$\mathrm{H}_{2}$ : The budgetcompilers in predicting the determination of the PAD budget estimates for the upcoming period uses the anchoring-adjustmentheuristic approach.

\section{Methodology of research}

This study is a quasi experimental study aimed to analyze the causal relationship with the methods of treatmenton variabel independent in order to obtain the expected results. This study used a $2 \times 2 \times 4$ design pattern between subject by fax order the realization of Local Revenue (PAD) information prior years (high and low) and fax order the realization of Local Revenue (PAD) information current year (high and low). Between subject design will compare the effects of different treatments on different subjects.

The data used in this study are primary data and are completed by filling out questionnaires using a Likert scale with intervals of one to five. The research population was individuals involved in the budget compilers for Local Revenue (PAD) in Makassar City. Respondents who were sampled were individuals who were involved in the team making up the PAD budget that met the criteria of having experience as a drafting team for a minimum of two years' budget. Each respondent was asked to fill in the amount of budget revenue predictions for the coming year with two treatments are different, namely of the treatment of representativeness and anchoring-adjustment.

The statistical test used in this research is two-way ANOVA, which is to find out the interaction between independent variables (information on the amount of past PAD budget for three years in a row ( $t$ $3),(t-2),(t-1)$ and information in the current year (t-0)\} is used. The dependent variable of this study is biased heuristics or the inaccuracy of predictions. ANOVA test criteria to determine acceptance or rejection of the hypothesis by using the $p$-value. Before testing the hypothesis, normality test and homogeneity test will be carried out as a condition for the ANOVA test.

\section{Research Results and Discussions}

Respondents or participants involved in quasi-experiment consisted of 26 individuals who were involved in the Local Revenue (PAD) budgeting team at Makassar City. Respondents in this study consisted of 9 women (34.6\%) and 17 men (65.4\%). Based on age, the majority of respondents were $69.2 \%$ (18 people) ranging from 31 to 40 years, 19.2\% (5 people) ranging from 27 to 30 years and the remaining $11.5 \%$ ( 3 people) aged over 40 years. The majority of respondents have high work experience, namely 13 people or $50 \%$ have worked between 6 to 10 years and 10 people (38.5\%) respondents have work experience between 2 to 5 years and the remaining 3 people (11.5\%) have experience over 10 years. While the majority of respondents in the field of economics as many as 24 respondents (92.3\%) and the rest other than the economic field as much as 2 people (7.7\%). Based on the description of the respondent, shows that the characteristics of respondents in this study have met the criteria for selecting the object of the study and the respondents have had sufficient knowledge and experience.

Based on the results of manipulation check, participant's perceptions of their confidence in the accuracy of the estimated amount of theLocal Revenue(PAD) budget had an average value of 4.27 in the range of values 1 (strongly disagree) to 5 (strongly agree). This indicates that participants have a high level of confidence in the accuracy of predictions (estimates) the amount of the Local Revenue (PAD) budget can be achieved in the coming period. Participants' perception of the importance of information on the amount ofLocal Revenue(PAD) budget realization for the previous years in determining the estimated PAD budget for the coming year shows an average value of 4.57 in the range of values 1 (strongly disagree) to value 5 (strongly agree). This indicates that treatment (trietment) given in the form of budget realization information Local Revenue (PAD) last year was effective and they need information PAD in previous years. Similarly, the participant's perception of the importance of the realization of the magnitude of the budget revenue information for years now in setting the amount of the estimated budget for the upcoming year shows an average value of 4.6 in a range of values from 1 (strongly disagree) to a value of 5 (strongly agree). This indicates that treatment (treatment) given in the form of budget realizationLocal Revenue (PAD) information for years now is an effective and they need information in current year revenue realization. As for the second type of question, regarding the understanding of participants in answering 
true or false statements about the correctness of information on the amount of Local Revenue (PAD) budget realization provided. All participants answered correctly $(100 \%)$. This shows that participants understand well the simulation material and the process of determining the estimated amount of theLocal Revenue(PAD) budget.

Fulfillment assuming the use of ANOVA that includes data normality test on inaccuracy of prediction using the Shapiro-Wilk test is $p=0.091$ for data representativeness and $p=0.263$ for data anchoringadjustment, is greater than alpha of 0.05 . This shows that the data is normally distributed. While the level of data homogeneity based on the Levene'stest shows that the statistical significance value of the levene for the inaccuracy of prediction $p=0,1$ and Local Revenue (PAD) estimation has $p=0.252$ greater than alpha of 0.05 . The results of this test reveals that variable dependent in each cell formed by the independent variable produces the same variant. In other words, the assumption of homogeneity of the variance of experiment research is fulfilled.

The test results using Two Way ANOVA,indicated that the lack of proper early prediction that occur between the behavior of the editorial team of Local Revenue (PAD) budget by using a representativeness heuristic approach and anchoring-adjustment heuristic approach in setting the Local Revenue (PAD) budget estimates for future periods differ significantly. This is evidenced based on the results of the $F$ test with a significance value $p=0.007$. In addition, based on the results of the $t$ test, the representativeness heuristic approach has a p-value of 0.023 or less than 0.05 . The relationship between the use of heuristic representativeness and unpredictability is significant or supports the first essay hypothesis. This shows that the budget compilers of Local Revenue (PAD) team uses representativeness heuristics (the existence of overreaction) in predicting the PAD budget determination for the upcoming year. In other words, the results of this study support the results of previous studies conducted by Barberis et al., 1998; Kaetsner, 2006; Boussaidi, 2013 and Habbe, 2017.

\begin{tabular}{|l|c|c|c|r|r|}
\hline \multicolumn{1}{|c|}{ Source } & Type III Sum of Squares & Df & Mean Square & F & Sig. \\
\hline Corrected Model & $7453,923^{\text {a }}$ & 7 & 1064,846 & 2,839 &, 016 \\
Intercept & 13,827 & 1 & 13,827 &, 037 &, 849 \\
Group & 2989,063 & 1 & 2989,063 & 7,968 &, 007 \\
Treatment & 1835,063 & 3 & 611,688 & 1,631 &, 196 \\
Group * Treatment & 1523,819 & 3 & 507,940 & 1,354 &, 269 \\
Error & 16505,637 & 44 & 375,128 & & \\
Total & 23959,563 & 52 & & & \\
Corrected Total & 23959,560 & 51 & & & \\
\hline
\end{tabular}

Table 1. Tests of Between-Subjects Effects

Dependent Variable: Inaccuracy of prediction

Table 2. Multiple Comparisons

Dependent Variable: Inaccuracy of prediction

\begin{tabular}{|c|c|c|c|c|c|c|c|}
\hline & \multirow{2}{*}{ (I) Treatment } & \multirow{2}{*}{ (J) Treatment } & \multirow{2}{*}{$\begin{array}{c}\text { Mean Difference (I- } \\
\mathrm{J})\end{array}$} & \multirow{2}{*}{ Std. Error } & \multirow{2}{*}{ Sig. } & \multicolumn{2}{|c|}{ 95\% Confidence Interval } \\
\hline & & & & & & Lower Bound & Upper Bound \\
\hline \multirow[t]{12}{*}{ LSD } & \multirow[t]{3}{*}{ Quadrant I } & Quadrant II & $-1,6185$ & 7,13599 & ,822 & $-16,0001$ & 12,7632 \\
\hline & & Quadrant III & ,7415 & 7,75350 & ,924 & $-14,8846$ & 16,3677 \\
\hline & & Quadrant IV & $19,2415^{*}$ & 8,14671 & ,023 & 2,8229 & 35,6601 \\
\hline & \multirow[t]{3}{*}{ Quadrant II } & Quadrant I & 1,6185 & 7,13599 & ,822 & $-12,7632$ & 16,0001 \\
\hline & & Quadrant III & 2,3600 & 7,30254 & ,748 & $-12,3573$ & 17,0773 \\
\hline & & Quadrant IV & $20,8600^{*}$ & 7,71875 & ,010 & 5,3039 & 36,4161 \\
\hline & \multirow[t]{3}{*}{ Quadrant III } & Quadrant I &,- 7415 & 7,75350 & ,924 & $-16,3677$ & 14,8846 \\
\hline & & Quadrant II & $-2,3600$ & 7,30254 & ,748 & $-17,0773$ & 12,3573 \\
\hline & & Quadrant IV & $18,5000^{*}$ & 8,29298 & ,031 & 1,7866 & 35,2134 \\
\hline & \multirow[t]{3}{*}{ Quadrant IV } & Quadrant I & $-19,2415^{*}$ & 8,14671 & 023 & $-35,6601$ & $-2,8229$ \\
\hline & & Quadrant II & $-20,8600^{*}$ & 7,71875 & ,010 & $-36,4161$ & $-5,3039$ \\
\hline & & Quadrant III & $-18,5000^{*}$ & 8,29298 & ,031 & $-35,2134$ & $-1,7866$ \\
\hline
\end{tabular}


Based on observed means.

The error term is Mean Square(Error) $=375,128$.

* The mean difference is significant at the, 05 level.

While the relationship between the use of anchoring-adjustment heuristic with the inaccuracy of the Local Revenue (PAD) budget prediction is not significant, because it has a $p$-value of 0.748 or does not support the second hypothesis. This shows that the budget compilers of Local Revenue(PAD) did not use anchoring-adjustmentheuristic (underreaction) in determining PAD budget estimates for the year that will be data. In other words, the results of this study do not support the results of previous studies conducted by Ashton, 1983; Mussweiler and Starck, 1999.

Based on the analysis above results indicate that the editorial team of the budget in predicting budget revenue for the upcoming year, rely heavily on informationof budget revenuerealization in previous years and information realization of Local Revenue (PAD) years now, which amount is equal to the revenue in the previous year (action overreaction). This is because the use of heuristic representativeness in planning the budget-setting revenue for years to come. Basically the budgeting team is always based on past and present information that is unchanging and consistent. Realization of budget revenue for the present that does not change or equal to budget information of past Local Revenue (PAD)realization, will shortly cause action overreaction behavior, namely PAD budget drafting team still does not change its decision in predicting revenue budget for the upcoming year. However, when information on Local Revenue (PAD) budget realization for the present period differs in an extreme manner, the Local Revenue (PAD) budget drafting team remains at the establishment or consistent, that the determination of PAD budget estimates for the upcoming year is based on information on the PAD budget for the previous years that did not change. Based on their experience in setting Local revenue (PAD) budget estimates, there is rarely a change in the extreme PAD realization.

\section{Conclusions and Limitations}

This study aims to examine and analyze the use of representativeness and anchoringadjustmentheuristic in determining the amount of Local Revenue(PAD) budget estimates for the upcoming period using quasi experiments. The results showed that the editorial team of the budget revenue in the public sector in Makassar City in setting the amount of budget estimates revenue for the future periodrequire information about realization of Local Revenue (PAD) inthe previous year and the realization of PAD in current year the same as the PAD years earlier, but did not pay attention information on the PAD budget for the current year is changing extreme. In other words, the budget compilers of Local Revenue(PAD) carries out behavior of the representativenessheuristic (overreaction behavior), but do not use an approach anchoring-adjustment (underreaction behavior) in determining Local Revenue(PAD) budget estimates for the coming year. This is due to the rare occurrence of extreme changes (there is a difference between the realization of the PAD in the previous years with the realization of the PAD in the current year). The limitation in this study is the small number of participants (respondents) and not randomly selected. This can interfere with the internal validity of the research. Future research development is indispensable, with a greater number of participants and adding psychological factors in decision-making that are expected to affect the determination of Local Revenue (PAD) budget estimates for the upcoming year.

\section{References}

1. Amaechi, O.C., Amadi, C.O., and Nnaji, S.E. (2018). Prebendalism and Budget Authorization in the Nigerian Legislature. International Journal of Academic Research in Business \& Social Sciences, 8(7), 59-73.

2. Ashton, R.H.(1983). Research in Audit Decision Making: Rationale, Evidence and Implications. Canadian Certified General Accountant's Research Foundation, Vancouver.

3. Amaechi, O.C., Amadi, C.O., and Nnaji, S.E. (2018). Prebendalism and Budget Authorization in the Nigerian Legislature. International Journal of Academic Research in Business \& Social Sciences, 8(7), 59-73.

4. Barberis, N., Shleifer, A., danVishny, R. (1998). A Model of Investor Sentiment. Journal of Financial Economics, 49(1), 1-53.

5. Bloomfield, R. Libby, R. and Nelson, M.W. (2000). Underreactions, Overreactions and Moderated Confidence. Journal of Financial Markets, 3(1), 113-137. 
6. Bloomfield, R. and Hals, J.(2002). Predicting the Next Step of a Random Walk: Experimental, Evidence of Regime-Shifting Belief. Journal of Financial Economy, 65(3), 397-414.

7. Bloomfield, R., Libby, R. and Nelson, M.W. (2003). Do Investors Overrely on Old Elements of the Earnings Time Series? Contemporary Accounting Research , 3(1), 1-31.

8. Boussaidi, R. (2013). Representativeness Heuristics, Investor Sentiment and Overre action to Accounting Earnings: the Case of the Tunisian Stock Market. Procedia-Social and Behavioral Sciences, 81(1), 9-21.

9. Bryant, P.(2007). Self-Regulation and Decision Heuristics in Entreupreneurial Opportunity Evaluation and Explotion. Management Decision. 45 (4), 732-748.

10.Chikeleze, O. (2002). Principles and Practice of Budgeting: With Public Sector Perspective. Enugu: Institute for Development Studies, University of Nigeria.

11.Del Valle, Gonzales, C. and Morron, E.(2001). The Budgetary Process in Peru: Is Budgetary Participatory Too Risk ?, Department of Economics, Universidad del Pacifico.

12.Epley, N. and Gilovich, T.(2004). Are Adjustment Insufficient? Personality and Social Psychology Bulletin, 30(1), 447-460.

13.Epley, N. and Gilovich, T. (2005). When Effortfull Thinking Influences Judgmental Anchoring: Differential Effects for Care and Incentives on Self-Generated and Externally Provided Anchors. Journal of Behavioral Decision-Making. 18(1), 199-212.

14.Epley, N. and Gilovich, T. (2006).The Anchoring and Adjustment Heuristics: Why the Adjustments Are Insufficient. Psychological Science. 17(1), 311-318.

15.Fadillah, I. (2017). Comparative Budget Analysis and Realization of Activities at Atma Husada Mahakam Mental Hospital in Samarinda. e Journal of Business Administration, 5(1), 67-78.

16.Fagley, N.S. (1988). Judgmental Heuristics: Implications for The Decision Making of School Psychologists. School Psychology Review, 17(1), 311-321.

17.Galotti, K.M. (2004). Cognitive Psychology: In and Out of the Laboratory. Third Edition. Belmont, CA: Wadsworth.

18.Garb, H.N.(1996). The Representation and Past Behavior Heuristics in Clinical Judgment. Professional Psychology: Research and Practice. 27(3), 272-277.

19.Gigerenzer, G. and Gaissmaier, W.(2011). Heuristics Decision Making. Annual Review of Psychology , 62(1), 451-482.

20.Habbe, A.H. (2017). Estimation Error of Earnings Information: A Test of Representativeness and Anchoring-adjustment Heuristics. International Journal of Economics and Financial Issues . 7 (1), 224-233.

21. Halim, A. (2002). Analysis of Variants of Regional Original Income in the Calculation Report of District/City Regional Revenue and Expenditure Budget in Indonesia. Doctoral Dissertation in Economics, UGM, Yogyakarta, Not Published.

22.Hardin, W. (1999). Bihavioral Research into Heuristics and Biases as an Academic Pursuit: Lessons from Other Disciplines and implications fir Real Estate. Journal of Property Investment \& Finance. 17(4), 333-352.

23.Henrizi, P. E, Hunziker, S and Himmelsbach, D. (2017). Anchoring and Adjustment Effects on Audit Judgments:Experimental Evidence From Switzerland. Austin Journal of Business Administration and Management, 1(2), 1-12.

24.Hogarth, R.M. and Einhorn, J.H.(1992). Order Effects in Belief Updating: The Belief-Adjustment Model. Cognitive Psychology, 24(1), 1-55.

25.Joyce, E.J. and Biddie, G.C. (1981). Anchoring and Adjustment in Prob abilistic Inference in Auditing. Journal of Accounting Research, 120-145.

26.Kaestner, M. (2006). Followis Earnings Anomalous Price Behavior Surprises: Does Representativeness Cause Overreaction?. Revue de I Association Francaise de Finance. 27(1), 5-31.

27.Kahneman, D. and Tversky, A. (1972). Subjective Probability: A Judgment of Representativeness. Cognitive Psychology , 3(1), 430-454.

28.Kahneman, D. and Tversky A. (1973). On the Psychology of Prediction, Psychological Review, 80(1), 237-251.

29.Kahneman, D. and Riepe, M.W. (1998). Aspects of Investor Psychology: Belief, Preferences and Biases Investment Advisors Should Know About. Journal of Porfolio Management,24(4), 52-65. 
30.Kannadhasan, M and Nandagopal. R.(2010). Influence of Decision Maker's Characteristic on Risk Analysis in Strategic Investment Decision. Journal of Modern Accounting and Auditing. 38-44.

31.Kuhn, D. and Siegler, R. (2006). Handbook of Child Psychology . Sixth Edition. Volume Two: Cognition, Perception and Language. New Jersey: John Wiley \& Sons, Inc.

32.Kuncoro, H. (2008) . Budget Variant and Realization of Budget, Case Study of Regional Government of DKI Jakarta Province. Journal of Applied and Theory Management , 1(2), 126-143.

33.LeBoeuf, R.A. and Shafir, E. (2009) . Anchoring on The Here and Now in Time and Distance Settings . Journal of Experimental Psychology: Learning, Memory and Cognition, 35(1), 81-93.

34.Marsden, A, Veeraraghavan, M. and Ye, M. (2008). Heuristics of Representativeness, Anchoring and Adjustment, and Leniency: Impact on Earnings: Forecasts by Australian Analysts. Quarterly Journal of Finance and Accounting, Vol. 47 (2).

35.Matlin, M.W. (1998). Cognitions. Fourth Edition. Harcourt Brace College Publishers.

36.McDermott, P.A. (1981). Sources of Error in Psychoeducational Diagnosis of Children. Journal of School Psychology , 19, 31-44.

37.Mussweiler, T. and Starck, F.(1999). Hypothesis-Consistent Testing and Semantic Priming in the Anchoring Paradigm: A Selective Accessity Model. Journal of Experimental Social Psychology , 35. 136-164.

38.Nelson, L.D. (2005). Advances in $t$ he Investigation and Application of the Anchoring and adjustment heuristic. Advances in Consumer Research , 32 (1), 125-128.

39.Nilsson, H. Juslin, P. and Olsson, H.(2008). Exemplars in the Mist: The Cognitive Substrate of Representationiveness Heuristic. Scandinavian Journal of Psychology. 49, 201-212.

40.Nofsinger, J.R. (2005). Psychology of Investing . Second Edition. New Jersey: Prentice-Hall, Inc.

41.Presutti, A.H. (1995). Anchor and Adjustment Heuistic Effect on Audit Judgment. Managerial Auditing Journal. 10, 13-21.

42.Rudolph, T.J and Popp, E. (2007). An Information Processing Theory of Ambivalence . Political Psychology , 28 (5), 563-585.

43.Saputro, F., Irianto, B.S. and Herwiyanti, E. (2016). Factors Influencing the Accuracy of the Public Sector Budget. Soedirman Accounting Review, 1(1), 21-39.

44.Shefrin, H. (2007). Corporate Behavioral Finance: Decision That Create Value. McGraw-Hill, Irwin.

45.Shah, A.K. and Oppenheimer, D.M.(2008). Heuristics Made Easy: An Effort-Reduction Framework. Psychological Bulletin, 134(2), 207-222.

46.Simmons, J.P., LeBoeuf, R.A. and Nelson, L.D.(2010). The Effect of Accuracy Motivation on Anchoring and Adjustment: Do People Adjust From Provided Anchors? Journal of Personality and Social Psychology , 99 (6), 917-932.

47.Strack, F. Bahnik, S. and Mussweiler, T.(2016). Anchoring: Accessibility as a Cause of Judgment Assimilation. Current Opinion in Psychology , 12, 67-70.

48.Sweller, J. and Sweller, S. (2006). Natural Information Processing Systems. Evolutionary Psychology , 4, 434-458.

49.Tamir, D.I. and Mitchell, J.P. (2013) . Anchoring and Adjustment During Social Inferences. Journal of Experimental Psychology: General , 142 (1), 151-162.

50.Tetlock, P.E.(2005). Gauging The Heuristic Value of Heuristics. Behavioral and Brain Sciences, 28 (4) , 562-563.

51.Turner, B.M. and Schley, D.R.(2016). The Anchor Integration Model: A Descrip tive Model of Anchoring Effects. Cognitive Psychology ,90(1), 1-47.

52.Tversky, A. and Kahneman, D. (1974). Judgment Under the Uncertainty: Heuristics and Biases. Science, 185: 1124-1131.

53.Wickham, P.A.(2003). The Representativeness Heuristics in Judgments Involving Entrepreneurial Success and Failure. Management Decision, 4(2), 156-167.

54.Yadav, S.M. (1994). How Buyers Evaluate Product Bundles: A Model of Anchoring and Adjustment. Journal of Consumer Research . 21(1), 342-353. 